\title{
ERP Application Research in Small and Medium-sized Printing Enterprises
}

\author{
Chunpeng $\mathrm{Li}^{1,2}$, Yinyin Wang ${ }^{1,2}$ \\ ${ }^{1}$. TSL School of Business and Information Technology, Quanzhou Normal University, Quanzhou, 362000, China, \\ 2. High Educational Engineering Research Center of Fujian Pronvince for E-Commerce Intelligent Based on Cloud \\ Computing and Internet of Things, Quanzhou, 362000, China,
}

\begin{abstract}
ERP system of Printing implementation has electronic computing and statistics. The various departments of information sharing and mutual control integrate printing companies in all sectors. It centralized management, saving a lot of resources. Small printing companies urgently need to implement an ERP system and improve economic efficiency. Printing ERP system implementation requires the scientific method. Otherwise it will reduce ERP efficiency. An additional investment of enterprises can influence enterprise decision makers.
\end{abstract}

Keywords- ERP; printing companies; management; process; SMEs.

\section{OVERVIEW OF PRINTING ENTERPRISE RESOURCE PLANNING SYSTEM}

Printing industry enterprise resource planning system is the printing industry management methods. Computer technology can produce the combination of the printing industry-specific enterprise resource management plans. Compared with the traditional artificial and paper management, the computing and statistics have responsibilities of belonging in place. Compared with excel spreadsheet, the scientific departments can share information and mutual control. To avoid information island generation, the various departments do not have timely data errors and problems. Compared with the widely used financial software, warehouse software, HR software, its printing industry production, scheduling, progress and other aspects of management have more professional, wider coverage, including the management of printing companies in all sectors.

\section{THE CHARACTERISTICS OF SMALL PRINTING BUSINESS ERP SYSTEM}

Compared with traditional ERP systems, ERP systems are printed with a distinctive characteristic of the printing industry. ERP systems are originated in the western manufacturing. Manufacturing ERP system is based on $\mathrm{BOM}$ as the core. Manufacturing and printing industry in the management difference is reflected in the manufacturing of products in the production of materials and workmanship. The printing industry products of different customer orders are often different. Namely, the manufacturing of the products are stable BOM, and printing industry products are not stable on BOM. Different customers in the printing industry, its products at different times of the materials and processes are often different in the production of printing on the need to put every single product materials and workmanship write understand. That industry has a fixed product files, and printing industry did not, in the printing industry in almost every single product is different. So if you apply the traditional printing business ideas designed ERP system will not be realized.

\section{THE NEED FOR SMALL AND MEDIUM SIZED PRINTING ENTERPRISES TO IMPLEMENT ERP}

With increasingly fierce competition in the printing industry, most corporate executives have recognized the need to improve the level of information. It makes full use of seeking to maximize the benefits. ERP implementation has become an inevitable trend in modern printing enterprise. First-order management needs of the printing industry have a special processing industry. Its MTO mode of production determines its operation and management of the particularity and complexity, such as processing varieties, short cycle orders, customer demand for flexible, complex production process, etc.; in recent years, printing companies have entered Boli stage. Rising labor costs raw material prices. Business managers have to consider how to cost-efficient operation. Finally enterprises Competitiveness requirements, according to the American Production and Inventory Control Society (APICS) statistics, you will receive implement ERP remarkable results. Inventory is decreased by $30 \%$ to $50 \%$; reduce delayed delivery of $80 \%$. Downtime should be reduced by $60 \%$ to reduce manufacturing costs by $12 \%$; improve management, management staff reduced by $10 \%$, production capacity increased by $10 \%$ to $15 \%$. ERP is a powerful tool to enhance the printing enterprise management level and competitiveness.

\section{SMALL AND MEDIUM ENTERPRISES TO IMPLEMENT ERP SIGNIFICANCE PRINTING}

ERP is printed between the printing business operations. The whole system of checks and balances can address human-caused effectively. Quotes, orders, production, with a single, hair outside, picking, storage, delivery goods, receivables and other aspects appear disjointed, enterprise information flow into a virtuous cycle of orderly process. Printing enterprise ERP applications, you can play the following role. 


\section{A. Streamline business processes and improve productivity}

Printing companies are in the absence of the implementation ERP systems, business orders, production and billing, financial closing, delivery, etc. They are generally required by the manual billing. It can not only easy to make mistakes, but a lot of work. The implementation of ERP systems, business unit entered only once, when the customer printed products again. You do not have the basic data re-entry. Because the software is set up in advance by all project processes. Personnel and omissions business craft personnel took place easily, reducing the chance of mistakes from the program.

Printing ERP system, according to the characteristics of the printing business and the actual situation of the industry, it is designed to be both advanced. Applicability can help companies manage a large number of personnel in the enterprise, dynamic, complex data and information timely. It accurately analysis and processing, production and business activities of the companies were in control and post feedback. So as to achieve rational use of corporate resources, reduce inventory, reduce capital occupied, enhance resilience, and enhance their market competitiveness and economic benefits.

\section{B. Real-time control of the production process}

After the business orders, production orders of construction paper craft have single computer on the current production tasks. Each workshop can be found in the ERP system requirements and corresponding printed pieces of data, within their respective mandates implementation of the production plan. The workshop with the department in advance to see the day's production tasks by ERP, staff and materials prepare timely production arrangements in question. Each workshop is equipped with a computer, in real-time entry into the production ERP systems. Production and operations staff views real-time progress of every single business.

\section{Supply chain management can achieve a reasonable distribution and material funds}

Printing ERP requirements analysis advanced materials. It can improve inventory management and work order materials budget. Work orders and other fixed picking optimization of resources effectively control costs. It can make the necessary printed pieces of paper, ink, and other accessories in a timely, accurate, and rationing. This not only ensures the business, production needs, but also reduce inventory.

\section{For fast, accurate, flexible printing quotes in valuation}

Customer inquiry is the beginning of the printing business. Quickly and accurately to customer quotes, is very important. ERP system is different, of valuation and pricing. Coefficient method and cost method valuation quoted have two ways. Quoted by the cost method, it is based on the cost of price plus the cost of profit quoted. Denominated costs include four parts. i) major direct material costs;

ii) prepress, printing, finishing costs;

iii) packaging and transportation costs;

iv) management fees, gains and taxes.

Quote approach is clear, concise and accurate.

\section{E. Implementation in accounts payable as a} fundamental cash flow management

ERP system can quickly check the completion of each task orders, delivery quantity, the number of returns. The amount of receivables and other records can quickly summarize customer receivables and credit conditions, to ensure the effective application of funds. There are prepayment of the inquiry process, a list of the receivables, accounts receivable summary, after the write-off of receivables management to settle. The function would advance the process. There is a list of corresponding payments, payables summary, after payment settled verification management, supplier statement function.

\section{V.MAIN FUNCTION OF SMALL PRINTING BUSINESS ERP SYSTEM}

Small printing business ERP system of main functions includes order management, service management, production management, logistics management. The cost of production management is receivables, payables piecework payroll management. The main function module quality management, equipment management, specifically the main functions are shown in Table 1.

TABle I. The Main Function Of The Small Printing Business ERP

\begin{tabular}{|l|l|}
\hline mainfunction & mainfunction \\
\hline Business unit management & Device Management \\
\hline Single Project Management & Transport Management \\
\hline $\begin{array}{l}\text { Production } \\
\text { management }\end{array}$ & Data Analysis \\
\hline Production schedule management & Department contact list \\
\hline Production Cost Management & User and rights management \\
\hline
\end{tabular}




\begin{tabular}{|c|c|}
\hline Purchasing Management & Price Audit Management \\
\hline $\begin{array}{l}\text { Product Information (table) } \\
\text { Management }\end{array}$ & $\begin{array}{l}\text { Automatic hand (paste) the } \\
\text { number of spin-off tracking }\end{array}$ \\
\hline Task Reminder Management & $\begin{array}{l}\text { Quality Control (QC processes, } \\
\text { product quality and product } \\
\text { quality) }\end{array}$ \\
\hline $\begin{array}{l}\text { Day management of all operations } \\
\text { departments statements }\end{array}$ & Quality management (iso quality) \\
\hline Customer Management & $\begin{array}{l}\text { Multiple audit management } \\
\text { (procurement, contracts, orders } \\
\text { and work orders) }\end{array}$ \\
\hline Accounts payable management & Decision Analysis \\
\hline Administration & Piece of program management \\
\hline Team management & $\begin{array}{llr}\begin{array}{l}\text { Intelligent } \\
\text { system }\end{array} & \begin{array}{c}\text { Platform } \\
\text { (mobile }\end{array} & \text { linking } \\
\text { function) } & & \end{array}$ \\
\hline
\end{tabular}

VI. THE SMALL PRINTING BUSINESS CRITICAL ERP IMPLEMENTATION

ERP enables businesses to benefit a lot. Not all businesses can implement ERP success, failure cases are uncommon. Small printing companies in the implementation of ERP should pay attention to control risks and strengthen the work of the following aspects.

\section{A. An emphasis on management, full participation}

ERP implementation, first attach great importance to the management. ERP project management organize framework for the establishment of a general manager in command, to determine a good project leader. To change the past, management, implementation and management are in philosophy of full participation.

\section{B. Select ERP software for enterprise needs}

Choosing from the reality of ERP business management software, it does not require full, chasing new. As in modern printing companies, it has chosen far less common ERP software, such as Peking University Founder. It associated company "Branch Indian ERP" management system. First, for the production printing business management issues need to be solved at present. It built entirely in the production management system as the core of the "production information data" to the inventory management system. On this basis, the implementation of financial management, human resources, etc., are not full and difficult.

\section{Full play to the efficiency of ERP}

The actual operation of the enterprise ERP system efficiency is only $40 \%$ to $60 \%$. Many of the advanced features should be used but did not play a role. To get ERP truly effective, we must build a strong organizational structure and give full play to its efficiency.

\section{Focus on the use of the system during maintenance and improvement}

ERP system in the maintenance and improvement of the problem can not be ignored. After the line runs out, system dedicated team and staff are engaged in ERP maintenance. Through the establishment of rules and regulations, standardize ERP applications and operating systems; use the system to an unreasonable restraint business processes and working methods. It would meet the various business units to improve efficiency.

\section{SUMMARY}

Printing ERP system implementation has electronic computing and statistics. The various departments of information sharing and mutual control integrate printing companies in all sectors. It centralized management and save a lot of resources to sort out the vulnerability. Management division enhances the economic efficiency of the printing business. With the development of information industry, it will continue to develop the printing business management systems. ERP systems have the ability to print and play every corner of the printing companies. Printing companies get the final high field.

Printing ERP systems is a business management tool for managers to solve the problem. It is a huge project, not just simple software to use. As an advanced management concepts, you need to execute a scientific method, otherwise can not play ERP efficiency. Additional investment of enterprises can influence enterprise decision makers.

\section{ACKNOWLEDGEMENTS}

This research was supported by the funds from:

i) Fujian province education department 2012JK project (number JK2012041): The applications of cloud computing and internet of things in the enterprise information public service platform.

ii) Construction Funds of Master Degree Awarded Unit of Quanzhou Normal University.

iii) Construction Funds of High Educational Engineering Research Center of of Fujian Pronvince for E-Commerce Intelligent Based on Cloud Computing and Internet of Things.

iv) The construction of key projects of Fujian province serving Haixi "Haixi port logistics information platform construction", Project Number: A103.

v) Science Plan Project of Fujian, Project Number: 2013R0087. 
vi) Science and technology Plan Project of Quanzhou, Project name: ERP Application Research in Small and Medium-sized Printing Enterprises of Quanzhou.

vii) Young Junior Teacher of Quanzhou Normal University.

\section{REFERENCES}

[1] Wu Yun. ERP can help force the printing business process reengineering [J]. Printing Industry, 2014, 01:64-65.

[2] Li Jingjing. modern printing business management of the roadPrinting ERP [J]. Guangdong Printing, 2012, 05:12-14.
[3] Dong Weifeng. Application of ERP in the printing business [J]. Market Weekly (theory), 2013, 05:35-36.

[4] Yanhong. ERP printing companies to bring new business opportunities [J]. Guangdong Printing ,2013, 03:7-8.

[5] Zhang Linjie. Analysis in the printing enterprise ERP application [J]. Science and Technology Information, 2012, 15:438-439.

[6] Haiyan. Printing companies thinking of ERP implementation [J]. Printing Technology, 2010, 19:60-61.

[7] Xunyue software. Http://www.xyerptech.com/. 